Nøklebye, A., Svalestuen, F., Fosse, R., Lædre, O. (2018). "Enabling Lean Design with Management of Model Maturity." In: Proc. 26 th Annual Conference of the International. Group for Lean Construction (IGLC), González, V.A. (ed.), Chennai, India, pp. 79-89. DOI: doi.org/10.24928/2018/0404. Available at: www.iglc.net.

\title{
ENABLING LEAN DESIGN WITH MANAGEMENT OF MODEL MATURITY
}

\author{
Andreas Nøklebye ${ }^{1}$, Fredrik Svalestuen², Roar Fosse ${ }^{3}$, and Ola Lædre ${ }^{4}$
}

\begin{abstract}
Traditional construction management has struggled with an ad hoc approach to design, increasing the number of negative iterations and sacrificing potential value. Building Information Modelling (BIM) has been driving information management in design, but its use has yet to be described in a way which makes it compatible with planning tools such as Last PlannerTM. Level of Development (LOD) could allow for this by attributing maturity to the BIM-model, yet previous studies of LOD implementation have shown potential for improvement. This paper researches current approaches, experiences and requirements for using maturity-based management in design.

A study of two large projects with maturity-based management using interviews and an analysis of measurements was conducted in addition to a literature scoping study.

The paper formulates five aspects of BIM-based workflows which needs to be addressed in order to manage their development. In addition, the study reveals how use of maturity-based management can provide a foundation for managing BIM-based workflows according to lean principles.

Finally, the paper concludes with practical recommendations for enabling lean design with management of model maturity, such as how to specify maturity levels or how to disaggregate the model into disciplinary sections.
\end{abstract}

\section{KEYWORDS}

Lean design, BIM, LOD, Set-Based Design (SBD), Last Planner

\section{INTRODUCTION}

Whereas production has a clear set of sequentially dependant, pre-defined tasks, design is better described as a set of interdependent, reciprocal iterations (Knotten et al. 2014). Because of this, the design workflow is much harder to manage, often resulting in an ad hoc approach (Carlos T. Formoso and Liedtke 1998; Knotten et al. 2017).

\footnotetext{
${ }^{1} \mathrm{MSc}$, Student, Department of Civil and Environmental Engineering, NTNU - Norwegian University of Science and Technology, 7491 Trondheim, Norway, Mobile +4745236866, asnoklebye@gmail.com

${ }^{2}$ PhD Candidate, NTNU/Veidekke, Trondheim, Norway, +4798673172, fredrik.svalestuen@ntnu.no

${ }^{3}$ Regional Manager, Lean Construction, Skanska, Oslo, Norway, +4793444588, roar.fosse@skanksa.no

${ }^{4}$ Associate Professor, dr.ing., NTNU, Trondheim, Norway, +4791189938, ola.laedre@ntnu.no
} 
With the evolution of information technologies over the last decades, several new tools have become available to designers, most notably Building Information Modelling (BIM). Although they have provided an effective way for integrating product information into the design process, especially when used together with Integrated Concurrent Engineering (ICE), these new tools are still being managed with a traditional mindset (Leite et al. 2011).

By planning and executing work according to lean principles, the Last Planner ${ }^{\mathrm{TM}}$ system has yielded significant returns when applied in the production phase of AECprojects. As such, similar improvements in the design phase could be attained by applying Last Planner ${ }^{\mathrm{TM}}$ to BIM-based workflows. However, BIM-based development lacks an orderly process, effectively making it incompatible with such planning tools.

The concept of Level of Development (LOD) was introduced as a means to formalize the development of a BIM-model (BIMForum 2017), and could be used as a way of attributing a work process to the BIM, making it compatible with Last Planner ${ }^{\mathrm{TM}}$. LOD has been approached in several ways (Abou-Ibrahim and Hamzeh 2016; Leite et al. 2011; McPhee 2013), yet lack of consistent understanding and utilization of LOD are common in projects (Hooper 2015), and no documentation regarding LOD as an enabler for Last Planner ${ }^{\mathrm{TM}}$ in BIM-based workflows could be found by the authors during the process of writing this paper. The research questions for the study were as follows:

1) What are current approaches to maturity-based management?

2) What are the experiences from maturity-based management?

3) What are the requirements for successful maturity-based management?

Five key aspects of BIM-based workflows were formulated from lean theory. These aspects were later examined in two large pilot projects using maturity-based management in order to present practical requirements for implementation and use.

\section{METHOD}

A literature scoping study was conducted to map existing literature on the topic. More than 130 of the most relevant scientific works were assessed from sources such as IGLC, Scopus and Compendex. In addition, general interviews were conducted with four professionals proficient in BIM and LOD in order to achieve a greater understanding of the field.

Two pilot projects using maturity-based management conducted by two of the largest Norwegian design build contractors (Skanska Norway and Veidekke Entreprenør AS) were studied using interviews with case practitioners ranging from managers to designers, in addition to a document study. All interviewees had prior experiences using Last Planner ${ }^{\mathrm{TM}}$ and ICE. All interviews were recorded and transcribed. Said transcripts were later verified by interview participants as representative of their views. Cases include Tiedemannsbyen, an apartment complex of five, six-storey buildings (Skanska, approx. \$54M, 14 designers), and E6: Arnkvern-Moelv, a 24km long Class A road project, part of the international E-road network (Veidekke, approx. \$260M, 30+ designers). 


\section{BACKGROUND}

\section{LEAN IMPLEMENTATION OF TOOLS}

Lean systems utilize standardization and continuous improvement in order to improve their practices (Moore 2007). By doing so, systems are enabled to dynamically adjust towards their lowest point of entropy, avoiding needless creation of waste in implementation efforts.

\section{LAST PLANNER ${ }^{\text {TM }}$ AND BIM IN DESIGN}

There exist several definitions of BIM, depending on whether one is addressing it as a model, a tool or a platform (Fosse et al. 2017). For the purposes of this paper, BIM is best described as a computerized foundation for an integrated collaborative design process (Jacob and Varghese 2012). This computer model consists of a sum of geometrical objects, each associated with certain disciplines. Development of the model is expressed through a series of iterations of said objects and their relationship relative to each other (Knotten et al. 2014), which eventually results in a digital representation of the final building.

The Last Planner ${ }^{\mathrm{TM}}$ system enables lean management by applying pull-based planning of tasks, thus reducing waste (Ballard 2000a). Some studies have proven the potential for applying Last Planner ${ }^{\mathrm{TM}}$ in building design (Fosse and Ballard 2016; Hamzeh et al. 2009), although only in limited applications. The challenge in doing so has been attributed to the differences in workflow between design and production (Grytting et al. 2017). To implement Last Planner ${ }^{\mathrm{TM}}$, one must thus be able to describe the iterative nature of design, assign responsibilities and relate these processes to a clear project development structure.

One of the primary differentiators of design and production is the fact that iterations in design can be both positive and negative (Ballard 2000b). As such, managing building design according to lean principles becomes a matter of reducing negative iterations while keeping the positive ones. The Toyota design approach (Set-Based Design) starts with mapping available design space and functional requirements for an object, then using input from different disciplines to narrow down the number of available concepts, converging towards a final design (Sobek et al. 1999). By determining the boundaries within which work will be conducted, workflow iterations are more likely to be positive, and thus value-creating for the project. Another benefit of this approach is the ability to systematically share incomplete information, a feature vital to the design process (Busby 2001).

\section{LOD}

Level of Development (LOD) is a measure of the reliability of the information associated with a specific object within the BIM, expressed as a series of levels (BIMForum 2017).

The application of LOD in construction design becomes apparent when viewing it in relation to Set-Based Design. The different levels of LOD expresses the gradual development of the BIM, specifiyng points of interest related to the increasing reliability of designs. This effectively describes the development of the model as a set of milestones 
relating to its attributes, which is a neccesity for using Last Planner ${ }^{\mathrm{TM}}$, seeing as the progressively developing work packages in design are hard to associate to its binary attitude towards task completion. In doing so, planners are enabled to pull certain generations of designs only when needed, thus reducing the risk of rework.

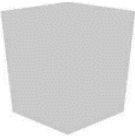

LOD100

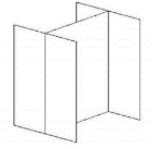

LOD200

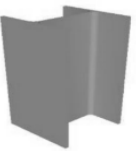

LOD300

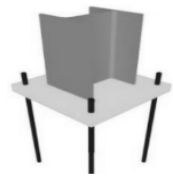

LOD350

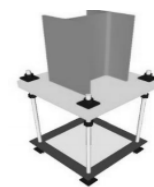

LOD400

Figure 1: Visual illustration of LOD-levels for a column (BIMForum 2017)

Table 1: Example of generic LOD-levels (BIMForum 2017)

\begin{tabular}{|c|c|}
\hline Levels & Description \\
\hline LOD100 & Graphical representation in the model as a symbol or a generic object. \\
\hline LOD200 & $\begin{array}{l}\text { Graphical representation in the model as a generic object with approximate quantities, } \\
\text { size, shape, location and orientation. }\end{array}$ \\
\hline LOD300 & $\begin{array}{l}\text { Graphical representation in the model as a specific object with quantities, size, shape, } \\
\text { location and orientation. }\end{array}$ \\
\hline LOD350 & $\begin{array}{l}\text { Graphical representation in the model as a specific object with quantities, size, shape, } \\
\text { location, orientation and interfaces with other building systems. }\end{array}$ \\
\hline $\begin{array}{l}\text { LOD400 } \\
\text { LOD500 }\end{array}$ & $\begin{array}{l}\text { Graphical representation in the model as a specific object with quantities, size, shape, } \\
\text { location and orientation with detailing, fabrication, assembly, and installation } \\
\text { information. }\end{array}$ \\
\hline & A field verified representation in regards to information and geometry. \\
\hline
\end{tabular}

Although possible to do on a per-object-level, it is often more practical to manage LOD-levels on a section basis when dealing with larger projects, combining multiple objects within the same room, floor, or similar to define larger sections of the BIM. The relative size of these sections ultimately determines the degree of specificity LOD will be managed in the project. In keeping with theory, the specificity should be managed in a way such that designers and other stakeholders are enabled to understand design development as two distinct processes. Firstly, the process of developing a specific section from idea towards production ready design, and secondly, the process of interactions and inter-dependencies between sections as they develop, influencing the design space and functional requirements of each other as they do so. In addition, effective concurrent communication can only be established once the model state is accurately communicated to designers. Surmising these aspects, theory dictates maturitybased design-approaches as presented in Table 2 . 
Table 2: Theoretical approaches to aspects of BIM-based workflows

\begin{tabular}{|c|c|}
\hline Aspect & Approaches from theory \\
\hline $\begin{array}{l}\text { Specification of } \\
\text { maturity levels }\end{array}$ & $\begin{array}{l}\text { Requirements for an object achieving a certain maturity should be related to } \\
\text { make-ready of future tasks. Being unrelated to the volume of detail, levels } \\
\text { should specify the necessary information for model progression towards value } \\
\text { creation. }\end{array}$ \\
\hline $\begin{array}{c}\text { Degree of model } \\
\text { disaggregation }\end{array}$ & $\begin{array}{l}\text { The disaggregation of the BIM into sections should be done in such a way that } \\
\text { the amount of information within one section remains comprehensible for all } \\
\text { designers, and so that all project participants are enabled to understand the } \\
\text { overall development of sections. }\end{array}$ \\
\hline $\begin{array}{l}\text { Communication of } \\
\text { model maturity }\end{array}$ & $\begin{array}{l}\text { The method of communicating the maturity levels of the different parts of the } \\
\text { model should enable designers to know the fitness of the information they are } \\
\text { working with, without being needlessly complicated to manage. }\end{array}$ \\
\hline $\begin{array}{l}\text { Planning and } \\
\text { control of workflow }\end{array}$ & $\begin{array}{l}\text { Planning tools for visualizing and optimizing flow of work during design, such } \\
\text { as Last Planner, should be used. LOD deliveries should be incorporated into } \\
\text { plans. }\end{array}$ \\
\hline $\begin{array}{l}\text { Responsibility for } \\
\text { assigning maturity }\end{array}$ & $\begin{array}{l}\text { In keeping with principles from Last Planner, having the designers declare the } \\
\text { maturity of their own work increases their ownership to tasks and } \\
\text { responsibilities. }\end{array}$ \\
\hline
\end{tabular}

\section{CURRENT APPROACHES}

\section{TIEDEMANNSBYEN}

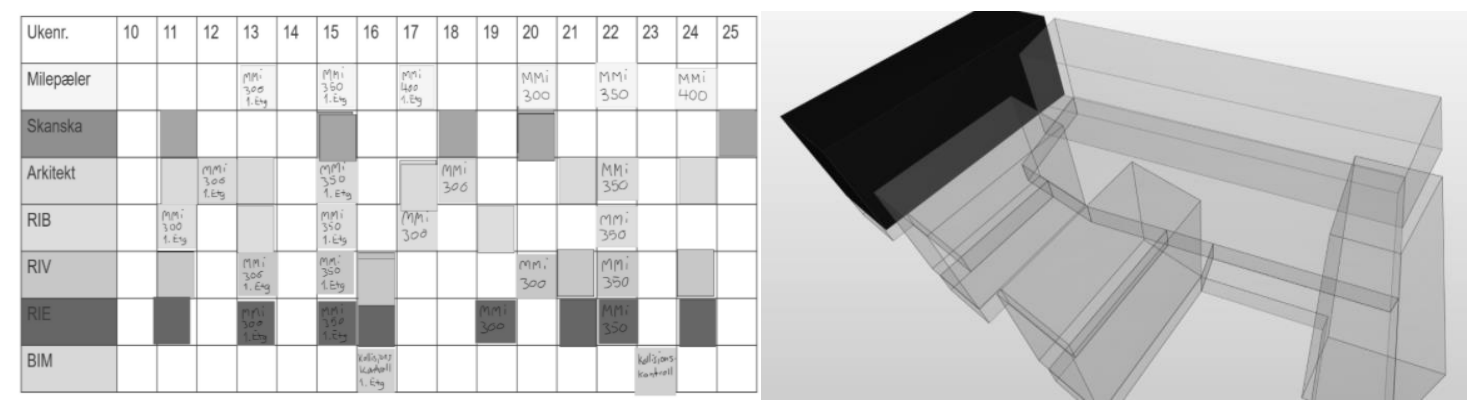

Figure 2: Model sections (left) and MMI-milestones in Last Planner (right)

Implementation of model maturity was done according to Skanska Norway's guidelines for using MMI (Model Maturity Index, which in practice uses the same maturity levels as LOD with simplified descriptions and the inclusion of a "MMI250"level"). The model was separated into ten sections, one for every basement and building in the complex (Figure 2). Maturity was assigned to all geometry managed by each discipline within each section. The design team was coordinated in ICE-sessions utilizing Last Planner ${ }^{\mathrm{TM}}$ for planning and control. Milestones for different sections achieving MMI was represented by post-it notes in Last Planner (Figure 2). Management opted not to develop a specific tool for communicating the development of model maturity, relying on designers being up to date regarding model maturity from the weekly ICE-sessions. 
Maturity deliveries for the 300-, and 350-level were controlled by BIM-coordinators. Maturity levels were tied to specific tasks that designers were required to accomplish. In addition, weekly charting of the number of collisions detected in the model was used as an indicator of progress, both externally and for the design team.

\section{E6: ARNKVERN-MOELV}
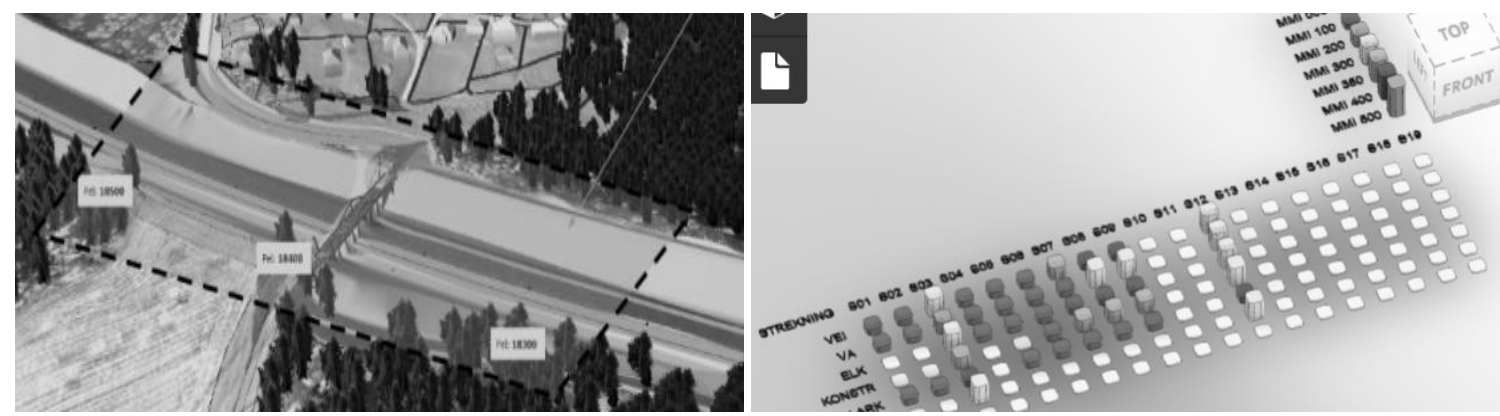

Figure 3: Example of section (left) and Visualization of MMI-levels, sections on $\mathrm{x}$-axis, disciplines on $\mathrm{y}$-axis (right)

Arnkvern-Moelv was conducted with a similar approach to Tiedemannsbyen, using similar maturity levels for large sections (Figure 3) in addition to ICE-meetings and Last Planner ${ }^{\mathrm{TM}}$. Differences include use of a 3D-chart for visualizing development of model maturity (Figure 3) and the absence of collision-control metrics to indicate progress. The exclusion of these metrics was not made because it was impossible to do, but rather the fact that it would not benefit the design process. This is a result of the project being a road, which generally is less constricted by small geometrical tolerances and intersections than building projects. MMI-levels were based on functional requirements for design deliveries, and often tied to specific tasks. Level requirements were adjusted per discipline in order to more accurately reflect individual functional requirements of different deliveries.

\section{EXPERIENCES FROM CURRENT APPROACHES RESULTS COMPARED TO TRADITIONAL APPROACHES}

Practitioners from both cases cited the following differences in design work compared to traditional practice:

- Increased understanding of the current state of the BIM model: Designers reported having an easier time understanding the extent to which they could rely on the information they were working with.

- Increased understanding of needs and responsibilities: Designers reported having a better understanding of what they were supposed to deliver, as well as providing clear guidance to other designers regarding what information they needed. 
- Increased sharing of incomplete information: As opposed to traditional means of withholding incomplete designs from other disciplines, designers were now enabled to systematically share qualified incomplete information.

- Increased ability for project participants to express project development: In contrast to traditional practice (having designers make subjective approximations of design development to external stakeholders), project progress was now quantifiable and easily understood by everyone.

The tracking of the number of model clashes for Tiedemannsbyen illustrates cultural inertia in adoption of new technologies. Performance was initially sub-par, the team missing all relevant deadlines for the first of the five buildings (Figure 4).
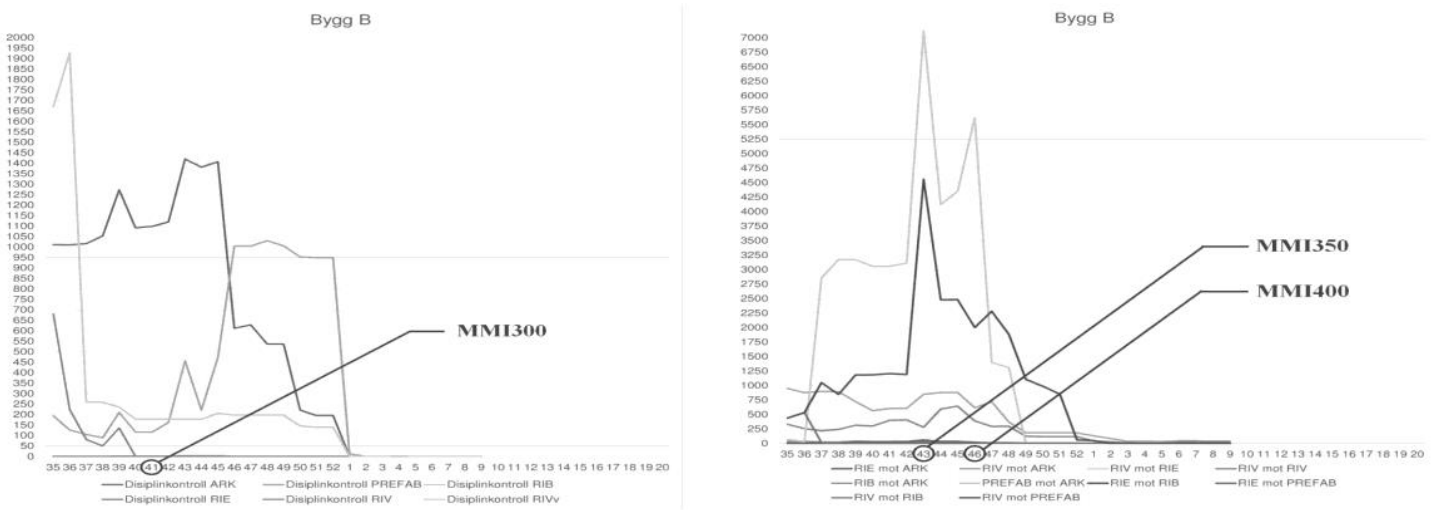

Figure 4: Weekly charting of the number of clashes within "Building B", disciplinary (left) and interdisciplinary (right), Tiedemannsbyen.

Although the team was unable to meet its deadlines for the first section, efficiency and reliability in meeting deadlines grew as the designers were increasingly exposed to the framework. Four months later, during the design of the third building, the model matured sufficiently to enable the same team to meet their deadlines (Figure 5).
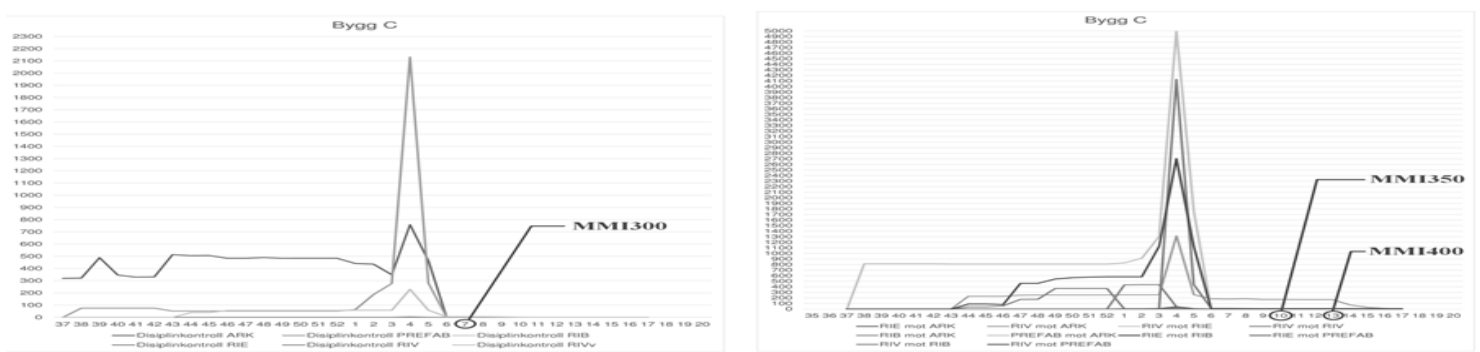

Figure 5: Weekly charting of the number of clashes within "Building C", disciplinary (left) and interdisciplinary (right), Tiedemannsbyen.

Although in some cases showing a slight tendency to inversely correlate to the number of tasks, Percent Plan Complete (PPC) remained around $80 \%$ for the entire project, while the number of tasks completed per week increased by $69 \%$ from the average number of tasks completed in weeks 36-1 to the averages recorded in weeks 2-10 (Figure 6). 


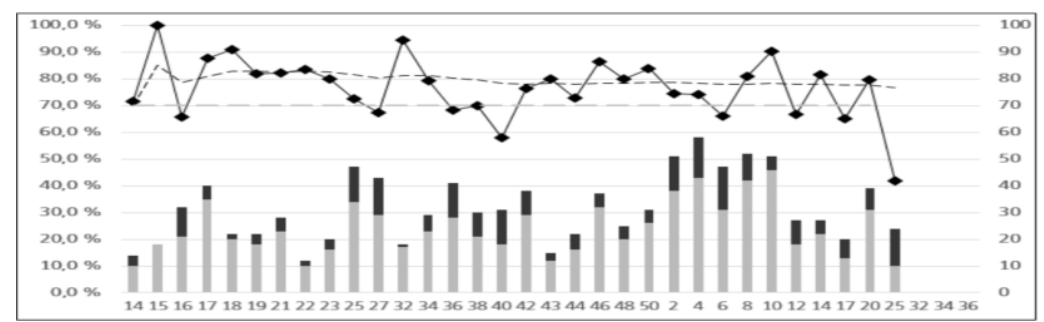

Figure 6: Tracking of PPC (linegraph) and number of tasks (bars), Tiedemannsbyen

It should be noted that Figures 4 and 5 reflect the total number of clashes in the BIM, including several cases of objects clashing with no relevance to constructability. However, this automated weekly chart generation requires little effort and is used to track trends rather than absolute number of clashes. More thorough clash reviews were performed specifically at MMI300 and 350 both by each discipline and by the project's design manager. Although some improvements are to be expected by designers throughout a design project, the trends in the graphs reveal a significant shift in practice, especially when considered relative to the increase in the total number of tasks completed per week.

\section{REFLECTION ON IMPLEMENTATION APPROACHES}

The following positive observations regarding implementation were made:

- Voluntary adoption by designers: As a sign of successful implementation, designers resolved to use the system rather than reverting to traditional practices.

- Management of maturity for large sections rather than individual objects was regarded as a factor for success: While remaining small enough for designers to comprehend the amount of information within each section, the larger sections made it easier for all project participants to understand the overarching flow of the project. Management of maturity on a per-object level would render this unfeasible.

- Simple visual aids greatly benefited designers: Graphing collisions per week as in Tiedemannsbyen or charting maturity in 3D as in E6: Arnkvern-Moelv exemplified relatively minor undertakings which greatly improved communication of model state, increasing the transparency of project flow for all participants.

- Case-specific adjustments were regarded as a factor for success: While keeping a certain level of standardization of the system, flexibility in including or excluding functionality based on unique project circumstances made implementation easier.

On the other hand, the following areas of improvement were discovered:

- Lack of clarity in MMI-level specifications: Designers cited somewhat ambiguous specifications for MMI-levels, which at times required subjective interpretations from the designers as to what they were supposed to deliver.

- Lack of software guidelines: Several minor issues hindering communication due to lack of clear guidelines for software use were reported. Designers were in some 
cases working with different datums and units, in addition to being unable to load different files due to server-side errors or faults related to naming conventions.

- Third party evaluation of model maturity required: Designer did on some occasions deliver models which was not mature enough to warrant a new MMIlevel. The inclusion of a BIM-coordinator evaluating deliveries proved necessary.

- Cultural inertia: As with any efforts to implement new methods, one of the greatest obstacles to success was the inability or reluctance of some designers to change their existing practices.

\section{REQUIREMENTS FOR SUCCESSFUL MANAGEMENT}

Positive results in implementation in both cases can largely be attributed to an approach of establishing a simple foundation for standardization and continuous improvement. The solutions to the first three aspects in each case illustrates this, where efforts have been made only to implement what is necessary for adjusting designers to a new way of working. After all, the tasks designers were responsible for carrying out were the same as before, the only difference being the process-related context now associated to the tasks. The importance of this approach is made further evident in the observation that cultural inertia was deemed to be one of the biggest obstacles for successful implementation. The results also highlight the fact that the software is in no way finalized or fool-proof, requiring management to pre-emptively address common pitfalls. This observation may serve as a reminder that design management is still an exercise in managing people, despite technological innovations.

The maturity-level specifications were discovered to have the most potential for improvement, being relatively simple in its current state. Although room for improvement was discovered, theory cannot go further than to suggest that these levels should reflect the functional requirements necessary for pull actuation of future tasks, recognizing that more detailed specifications of levels would differ with discipline and type of project.

The management approach of separating models into larger sections and managing these sections by discipline, rather than trying to manage individual objects, was determined to be a factor underpinning success in both cases, serving as a better way of explaining the overall model development from concept to final design.

Although both projects illustrated a necessity for standardization of practice, having some flexibility in management approaches was also deemed necessary. The solution to this issue given in the cases was to standardize functionality, yet provide the ability for management to choose which functionality to implement on a case by case basis.

\section{CONCLUSION}

Findings illustrate that there is a theoretical case to be made for maturity-based management as an enabler for using Last Planner ${ }^{\mathrm{TM}}$ in BIM workflows, and that experiences from case studies seem to support this notion. In practical terms, projects utilizing maturity-based management indicates a greater ability to communicate model state and progress as well as designer needs and responsibilities, resulting in the design 
process being more transparent and manageable. Successes in adoption can be attributed to a practice of utilizing standardization and continuous improvement while still allowing for a certain degree of flexibility in project implementations.

Based on theory and experiences from case studies, recommendations for using maturity-based management of BIM workflows are as listed in Table 3.

Table 3: Management recommendations based on theory and case experiences

\begin{tabular}{|c|c|}
\hline Aspect & Recommendations \\
\hline $\begin{array}{l}\text { Specification of maturity } \\
\text { levels }\end{array}$ & $\begin{array}{l}\text { Maturity-levels are based on the future functional needs, formulated as } \\
\text { specific tasks. Tasks are specified for each level, per respective discipline. }\end{array}$ \\
\hline $\begin{array}{l}\text { Degree of model } \\
\text { disaggregation }\end{array}$ & $\begin{array}{l}\text { Segregation of model into sections as large as possible without making the } \\
\text { amount of information for each discipline within each section } \\
\text { incomprehensible for designers (Examples: Figures } 2 \& 3 \text { ). }\end{array}$ \\
\hline $\begin{array}{l}\text { Communication of } \\
\text { model maturity }\end{array}$ & $\begin{array}{l}\text { Visualization of maturity per discipline, per section in a chart, possibly } \\
\text { excel (Examples: Figure } 3 \text { ). }\end{array}$ \\
\hline $\begin{array}{l}\text { Planning and control of } \\
\text { workflow }\end{array}$ & $\begin{array}{l}\text { Last Planner }{ }^{\mathrm{TM}} \text { and ICE. Milestones for maturity-levels are attributed to } \\
\text { post-it notes used as deliveries in collaborative planning. }\end{array}$ \\
\hline $\begin{array}{l}\text { Responsibility for } \\
\text { assigning maturity }\end{array}$ & $\begin{array}{l}\text { Designers should feel ownership to the maturity of their tasks, although an } \\
\text { independent evaluation of maturity may prove necessary until level- } \\
\text { requirements has been sufficiently standardized to avoid } \\
\text { misunderstandings. }\end{array}$ \\
\hline
\end{tabular}

It should be noted that a vital point of success for implementation in both cases has been the simplicity in their approach, as well as successful, project-specific choices made by management. Having historically been approached as an object-level attribute, one could make the case that failed LOD implementations in the past have been a result of pushing needless functionality instead of pulling technologies from project needs. After all, the positive yields documented in this study does not come from a radical change in practice, but rather a simple approach of associating existing work and tools to project development.

\section{REFERENCES}

Abou-Ibrahim, H., and Hamzeh, F. (2016). BIM: A TFV Perspective to Manage Design Using the LOD Concept. Proceedings 24th. Annual Conference of the International Group for Lean Construction, Heraklion, Greece, pp. 465-473.

Ballard, G. (2000a). The Last Planner System of Production Control. The University of Birmingham, Faculty of Engineering.

Ballard, G. (2000b). Positive vs Negative Iteration in Design. Proceedings 17 th Annual

Conference of the International Group for Lean Construction, Brighton, UK.

BIMForum. (2017). "Level of Development Specification Part I." <http://bimforum.org/lod/> (Jan. 23, 2018). 
Busby, J. (2001). "Error and Distributed Cognition in Design.” Design Studies, 22, 233254.

Carlos T. Formoso, Patrícia Tzotzopoulos, Margaret S. S. Jobim, and Liedtke, R. (1998). Developing a Protocol for Managing the Design Process in the Building Industry. Proceedings 6th. Annual Conference of the International Group for Lean Construction, Guarujá, Brazil.

Fosse, R., and Ballard, G. (2016). Lean Design Management in Practice with the Last Planner System. Proceedings 24th. Annual Conference of the International Group for Lean Construction, Boston, MA, USA, pp. 33-42.

Fosse, R., Ballard, G., and Fischer, M. (2017). "Virtual Design and Construction: Aligning BIM and Lean in Practice." 499-506.

Grytting, I., Svalestuen, F., Lohne, J., Sommerseth, H., Augdal, S., and Lædre, O. (2017). "Use of LoD Decision Plan in BIM-projects." Procedia Engineering, Creative Construction Conference 2017, 19-22 June 2017, Primosten, Croatia, 196, 407-414.

Hamzeh, F. R., Ballard, G., and Tommelein, I. D. (2009). Is the Last Planner System Applicable to Design? A Case Study. Proceedings 17th Annual Conference of the International Group for Lean Construction, At Taipei, Taiwan, pp: 165-176.

Hooper, M. (2015). Automated model progression scheduling using level of development. Department of Construction Sciences, Lund University, Lund, Sweden.

Jacob, J., and Varghese, K. (2012). A model for product-process integration in building industry using Industry Foundation Classes and Design Structure Matrix. Construction Research Congress 2012, pp. 582 - 590.

Knotten, V., Lædre, O., and Hansen, G. K. (2017). Building design management - key success factors. Architectural Engineering and Design Management, 13:6, 479-493,.

Knotten, V., Svalestuen, F., Dammerud, H., and Aslesen, S. (2014). Integrated methodology for design management - a research project to improve design management for the AEC industry in Norway. Proceedings 22nd Annual Conference of the International Group for Lean Construction, At Oslo, Norway, Volume: Vol 3.

Leite, F., Akcamete, A., Akinci, B., Atasoy, G., and Kiziltas, S. (2011). Analysis of modeling effort and impact of different levels of detail in building information models. Automation in Construction, 20:5, pp 601-609.

McPhee, A. (2013). "What is this thing called LOD." Practical BIM blogspot, <http://practicalbim.blogspot.no/2013/03/what-is-this-thing-called-lod.html> (Jan. 22, 2018).

Moore, R. (2007). Selecting the Right Manufacturing Improvement Tools. Elsevier Science \& Technology.

Sobek, D., Ward, A. C., and Liker, J. (1999). Toyota's Principles of Set-Based Concurrent Engineering. 